\title{
Novel Insight into the Intricate Shape of Flax Fibre Lumen
}

\author{
Emmanuelle Richely $^{1}{ }^{(D}$, Sylvie Durand ${ }^{1}$, Alessia Melelli ${ }^{2} \mathbb{D}$, Alexander Kao ${ }^{3}$, Anthony Magueresse ${ }^{2} \mathbb{D}$, \\ Hom Dhakal ${ }^{4}{ }^{(D)}$, Tatyana Gorshkova ${ }^{5}$, Franck Callebert ${ }^{6}$, Alain Bourmaud ${ }^{2} \mathbb{D}$, Johnny Beaugrand ${ }^{1}$ \\ and Sofiane Guessasma ${ }^{1, *}$
}

1 INRA-UR1268 Biopolymers Interactions and Assemblies (BIA), CEDEX 03, BP 71627-44316 Nantes, France; emmanuelle.richely@inrae.fr (E.R.); sylvie.durand@inrae.fr (S.D.); johnny.beaugrand@inrae.fr (J.B.)

2 IRDL, University of Southern Brittany, UMR CNRS 6027, 56100 Lorient, France; alessia.melelli@univ-ubs.fr (A.M.); anthony.magueresse@univ-ubs.fr (A.M.); alain.bourmaud@univ-ubs.fr (A.B.)

3 Elettra Sincrotrone Trieste SCpA, 34149 Trieste, Italy; alex.kao.port@gmail.com

4 AMM Research Group, University of Portsmouth, Hampshire PO13DJ, UK; hom.dhakal@port.ac.uk

5 Kazan Institute of Biochemistry and Biophysics, FRC Kazan Scientific Center of RAS, 420111 Kazan, Russia; gorshkova1953@mail.ru

6 Groupe Depestele, 14540 Bourguébus, France; fcallebert@depestele.com

* Correspondence: sofiane.guessasma@inrae.fr; Tel.: +33-(0)240675036

Citation: Richely, E.; Durand, S.;

Melelli, A.; Kao, A.; Magueresse, A.; Dhakal, H.; Gorshkova, T.; Callebert, F.; Bourmaud, A.; Beaugrand, J.; et al. Novel Insight into the Intricate Shape of Flax Fibre Lumen. Fibers 2021, 9, 24. https://doi.org/10.3390/fib9040024

Academic Editor: Gea Guerriero

Received: 18 February 2021

Accepted: 1 April 2021

Published: 6 April 2021

Publisher's Note: MDPI stays neutral with regard to jurisdictional claims in published maps and institutional affiliations.

Copyright: (C) 2021 by the authors. Licensee MDPI, Basel, Switzerland. This article is an open access article distributed under the terms and conditions of the Creative Commons Attribution (CC BY) license (https:/ / creativecommons.org/licenses/by/ $4.0 /)$.

\begin{abstract}
Plant fibres and especially flax can be distinguished from most synthetic fibres by their intricate shape and intrinsic porosity called lumen, which is usually assumed to be tubular. However, the real shape appears more complex and thus might induce stress concentrations influencing the fibre performance. This study proposes a novel representation of flax fibre lumen and its variations along the fibre, an interpretation of its origin and effect on flax fibre tensile properties. This investigation was conducted at the crossroads of complementary characterization techniques: optical and scanning electron microscopy (SEM), high-resolution X-ray microtomography $(\mu \mathrm{CT})$ and mechanical tests at the cell-wall and fibre scale by atomic force microscopy (AFM) in Peak-Force Quantitative NanoMechanical property mapping (PF-QNM) mode and micromechanical tensile testing. Converging results highlight the difficulty of drawing a single geometric reference for the lumen. AFM and optical microscopy depict central cavities of different sizes and shapes. Porosity contents, varying from 0.4 to $7.2 \%$, are estimated by high-resolution $\mu \mathrm{CT}$. Furthermore, variations of lumen size are reported along the fibres. This intricate lumen shape might originate from the cell wall thickening and cell death but particular attention should also be paid to the effects of post mortem processes such as drying, retting and mechanical extraction of the fibre as well as sample preparation. Finally, SEM observation following tensile testing demonstrates the combined effect of geometrical inhomogeneities such as defects and intricate lumen porosity to drive the failure of the fibre.
\end{abstract}

Keywords: porosity; internal structure; X-ray microtomography; scanning electron microscopy; lumen; flax fibre

\section{Introduction}

Contrary to most synthetic fibres, plant fibres present an intrinsic porosity. The central cavity is filled with cytoplasm and organelles during cell life and the lumen is formed after the death of the plant [1,2]. In addition, small internal cavities with diameters of a few $\mu \mathrm{m}$ were also reported as contributors to the porous structure of plant fibres [3-5]. This distinctive characteristic can be involved in the generation of stress concentrations, leading to the failure of the fibre $[3,6,7]$. Moreover, porosities in plant fibres are also the location of free water filling at high moisture content. This water is involved in the hydric expansion coefficients of the fibre, and, in other words, determines its dimensional characteristic [8] and related hygromorph properties [9]. From an engineer or material scientist point of view, porosity is an important characteristic of plant fibres to deal with in order to tailor 
plant fibre composites. In composite application, the filling of the large internal lumen of sisal with resin shows beneficial properties such as better water absorption resistance, strengthening of the bonding between microfibrils and hindering of crack propagation [10]. However, the resin penetration is dependant on the lumen size and composite processing parameters. In the case of flax, the lumen has been depicted as a site of crack initiation at the composite scale [11].

The lumen size varies greatly depending on the cell type function in plants, and several authors described the porosity content of plant fibres (Figure 1). Measurements are often based on transversal observations of fibres or stems embedded in a resin and further image processing. Sisal fibres, for instance, contain a very high lumen content exceeding $25 \%$ of the total fibre area $[10,15]$. Other bast fibres such as hemp and flax present a smaller lumen partly explaining their interesting mechanical properties for the biocomposite industry. Indeed, more than 500 cottonised flax fibres were analysed by Aslan et al. [12] who reported $85 \%$ of the fibres with a lumen content lower than $1 \%$, and a mean lumen content of $1.6 \%$. Charlet et al. [1] reported a mean porosity of $3 \pm 2 \%$ for flax fibres extracted from the middle of the stem. Fibres extracted from the bottom of the stem showed a slight increase in lumen content, with a mean value of $4 \pm 2 \%$, revealing possible intra-stem variabilities and a maturity effect, already highlighted in the case of hemp [17]. Another study conducted by Charlet et al. [13] on the same flax variety harvested the same year led to a higher mean porosity content of $6.8 \pm 3.5 \%$, underlying variabilities in lumen size. The discrepancies revealed by Charlet et al. [13] might partly be explained by the fact that the measurements are based on images taken at a single location along the fibres. However, the cell wall thickness and lumen size vary lengthwise, leading to discrepancies within a batch depending on the location at which the fibres are cut due to intra-fibre variability. Moreover, inter-fibre variabilities were also reported, as the lumen size seems to vary from one fibre to another. The reasons for this inter-fibre variability still remain unclear. Several authors $[6,18]$ tackled the correlation between the diameter of the fibre and its porosity content. De Rosa et al. [19] highlighted these variabilities by showing that lumen diameters of Okra fibres vary between 0.1 and $20 \mu \mathrm{m}$. The influence of the growing conditions on the lumen size of hemp fibres was investigated by Schäfer et al. [16]. Indeed, they reported a higher proportion of cell lumen in 1998 (16.2\%) than in 1999 (12.9\%), probably linked to the drought of 1998.

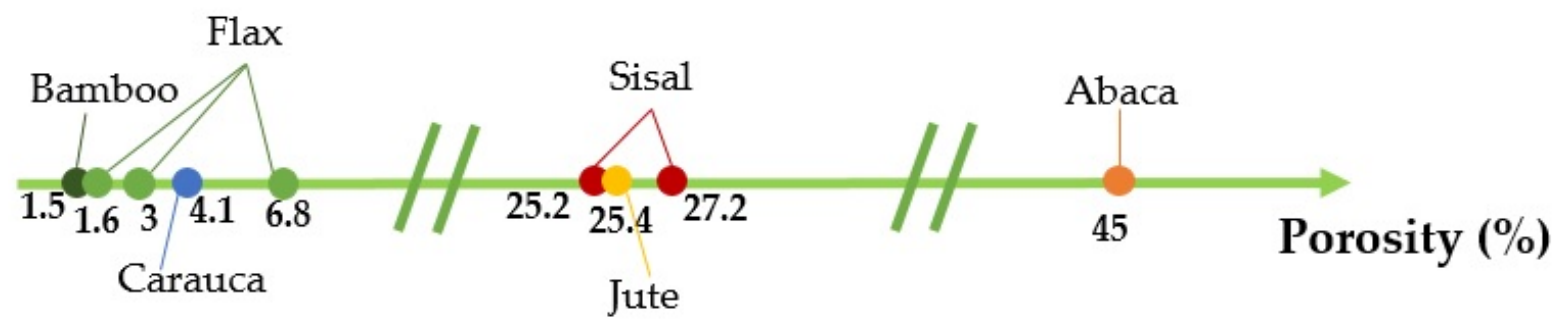

Figure 1. Lumen/total surface ratio (\%) for different plant fibres; from [1,12-16].

Due to the small size of fibres and resulting experimental difficulties, the fine characterization of the inherent porosity along plant fibres remains a challenge. The variations in lumen size along hemp fibres and bundles were described by Beaugrand et al. [6] thanks to X-ray microtomography. Abbey et al. [20] conducted another study using $\mu \mathrm{CT}$ on flax unitary fibres. They were able to describe small internal cavities within the fibre. These voids are considered defects and are expected to influence fibre strength. The work was further developed in Thuault's thesis [3], depicting a change in diameter along the fibre and cavities from 1 to $5 \mu \mathrm{m}$ in diameter.

However, one can point out that available data on flax lumen are scarce and often limited to a single location along the fibre or a single characterization technique. Moreover, deciphering the origin and consequences of these lumen variabilities remains a challenge. In order to overcome these issues, the research methodology developed in this study is 
as follows: combine high-resolution surface and volume information in order to better (I) morphologically characterize and (II) understand the origin and consequences of the intricate lumen shape of flax. Therefore, this work includes complementary up-to-date measurement techniques including optical and atomic force microscopy (AFM) as well as high-resolution X-ray microtomography performed at the fibre scale to characterize the structure and arrangement of the central lumen. Finally, the interaction between lumen and defects in driving the failure of fibres is shown by conducting scanning electron microscopy (SEM) on a fracture surface following tensile testing of flax fibres. The observation techniques, their respective spatial resolution in this study and their main advantages are summarised in Figure 2.
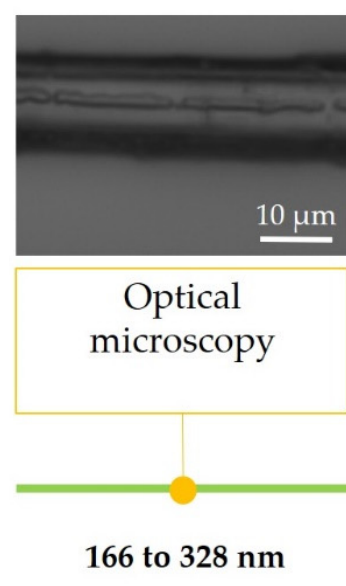

$2 \mathrm{D}$

Native state

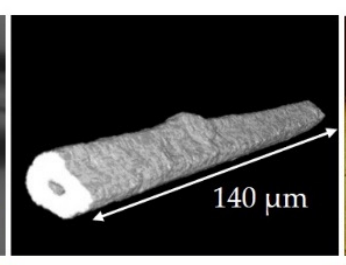

X-ray

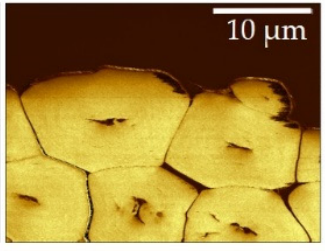

Atomic force microscopy (PF-QNM)

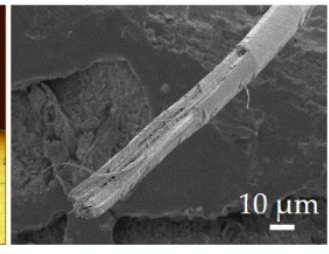

Scanning electron microscopy

\section{microtomography}

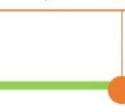

$50 \mathrm{~nm}$

50 to $75 \mathrm{~nm}$

2D

3D

Native state, 3D

Stiffness mapping
Spatial resolution

2D

Topological information

Figure 2. Multi-scale observation techniques and distinctive characteristics exploited in this study.

\section{Materials and Methods}

\subsection{Materials}

Scutched flax fibres (Linum usitatissimum L.) from the Bolchoï variety were provided by Groupe Depestele/Teillage Vandecandelaère (Bourguebus, France). The plants were cultivated in 2017 in Normandy, France, and dew-retted in the field. Fibre extraction was achieved by industrial scutching. The fibre batches were then stored in a controlled environment and protected from light. The location of the bast fibres of interest to the biocomposite industry within the stem is highlighted in Figure 3a. The bundles resulting from industrial scutching and unitary fibre glued on a paper frame are observed in Figure $3 b, c$, respectively.

\subsection{X-ray Tomography Imaging}

X-ray microtomography was performed on a Xradia 510 Versa tomograph (Zeiss, Marly-le-Roi, France). The voltage was set to $50 \mathrm{keV}$, with a sample-detector distance of $28 \mathrm{~mm}$ and a $\mathrm{x}-\mathrm{y}$ dimension of the reconstructed slices of $(840$ to 872$) \times 976$ pixels. A voxel size of $150 \mathrm{~nm}$ was reached, allowing to scan 2 unitary flax fibres " $a$ " and " $b$ " and a bundle "c" composed of 2 fibres " $c 1$ " and "c2" over a length of 137 to $140 \mu \mathrm{m}$. After the acquisition, image processing was conducted on resulting scans with the software FIJI (fiji.sc/) and the additional plugin Morpholibj developed by Legland et al. [21]. A 3D gradient filter was applied to the 8-bit transversal image stacks in order to better reveal the boundaries of elements. The fibre outlines were obtained by a watershed segmentation with adjusted tolerance. A mask was created by binarising the resulting segmentation and merging areas. The masks and initial grey-scale images were superimposed to verify the 
accuracy of the results. The form factor and surface areas of the filled fibres were calculated for each cross-section along the fibre. The internal porosities were obtained by multiplying the latter mask by the initial grey-scale image and applying a threshold. Only surface areas of objects of interest featured above $0.08 \mu \mathrm{m}^{2}$ were taken into account in the calculations to reduce the noise effects. An initial grey-scale image and final processed cross-section of fibre "a" are presented in Figure 4, with their related intensity profile along the plotted line. The external outlines of the fibre were defined at the limit between the bright and dark areas. Regarding internal porosities, as it was difficult to define an optimal threshold, a range of possible thresholds was selected instead and the median value was adopted for latter quantifications. The range of thresholds chosen in the case of fibre " $a$ " is represented on the line plot of Figure $4 a$, and the resulting porosity content along the fibre is shown in Figure 5 for the median and extremum threshold values.

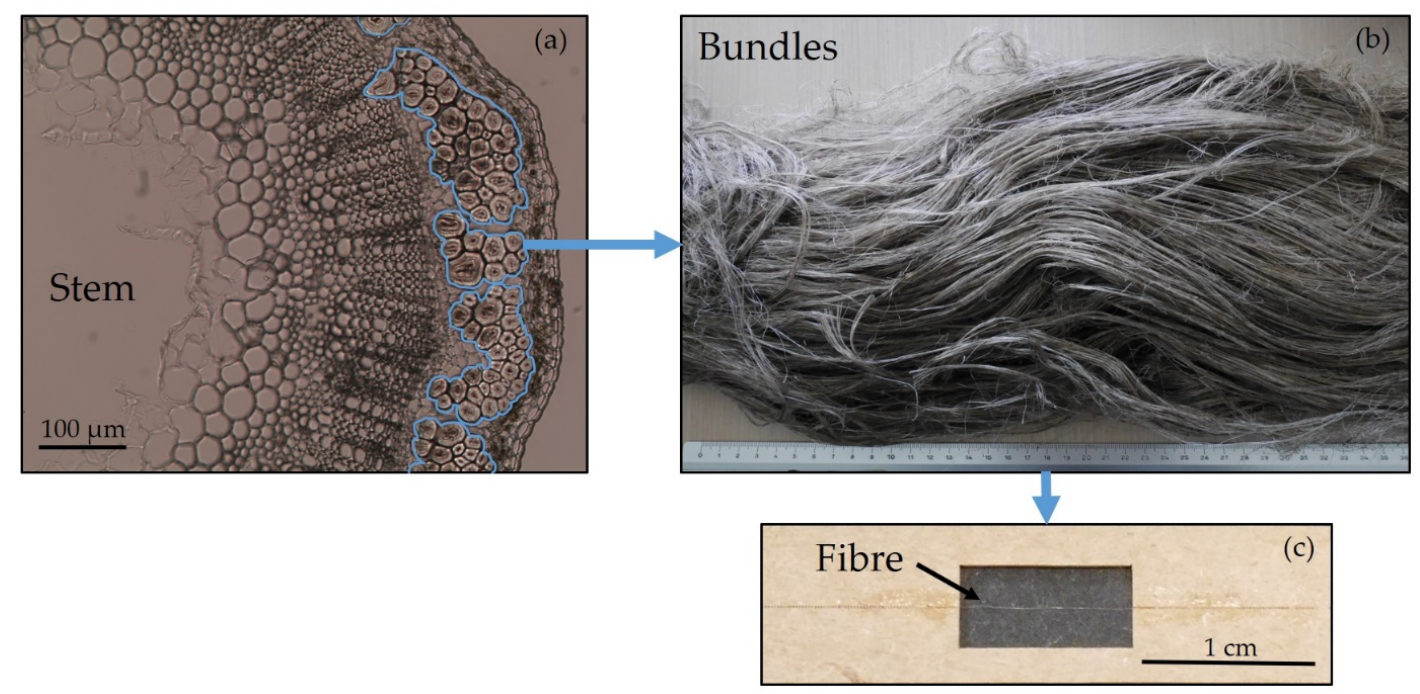

Figure 3. (a): Flax stem cross-section and highlight of the bast fibres location; (b): bundles of flax fibres resulting from industrial scutching (centimetric scale); (c): Unitary fibre glued on a paper frame.
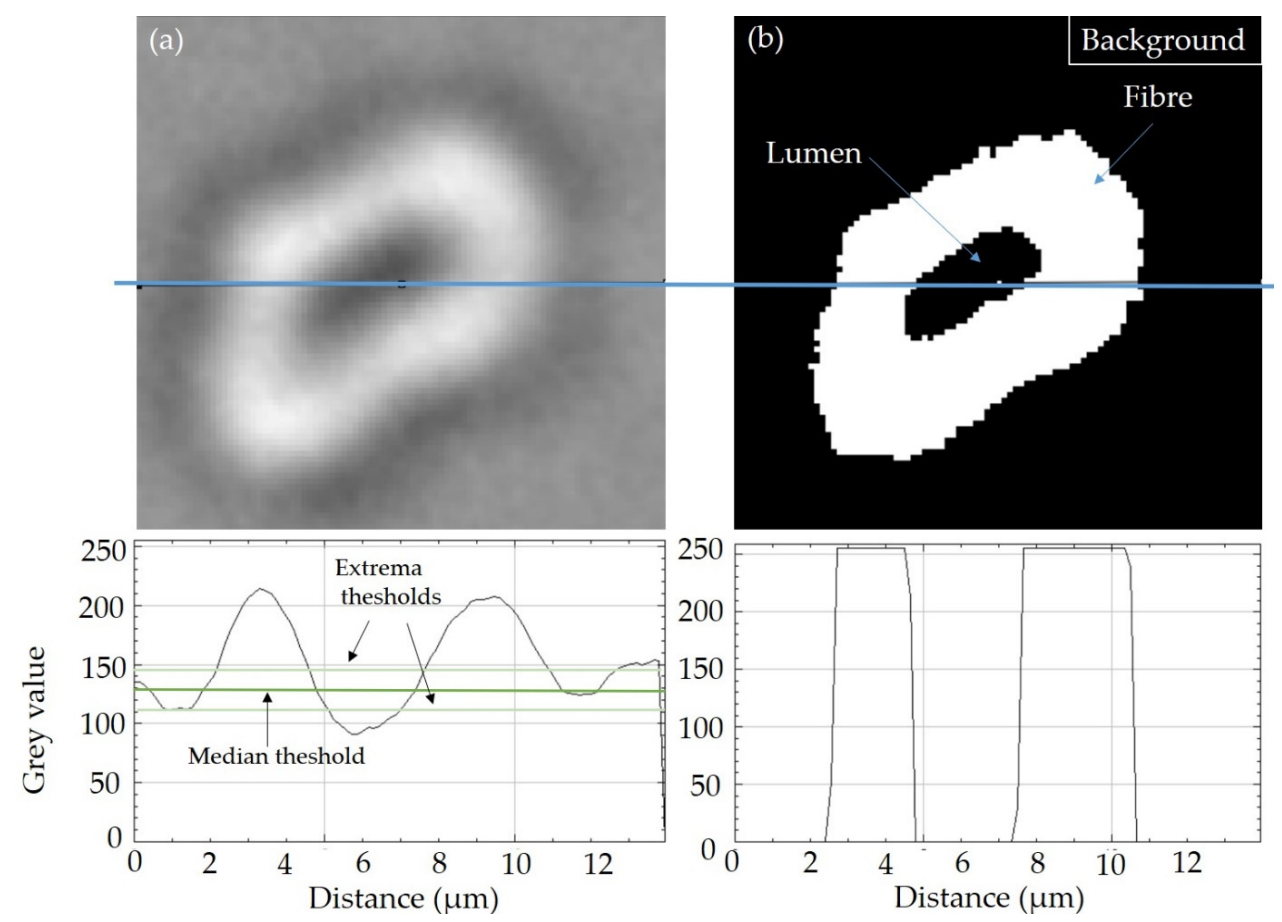

Figure 4. Example of X-ray tomography image processing, from (a) a greyscale cross-section of fibre "a" to (b) a binary image and related grey-scale level along the line (bottom). 


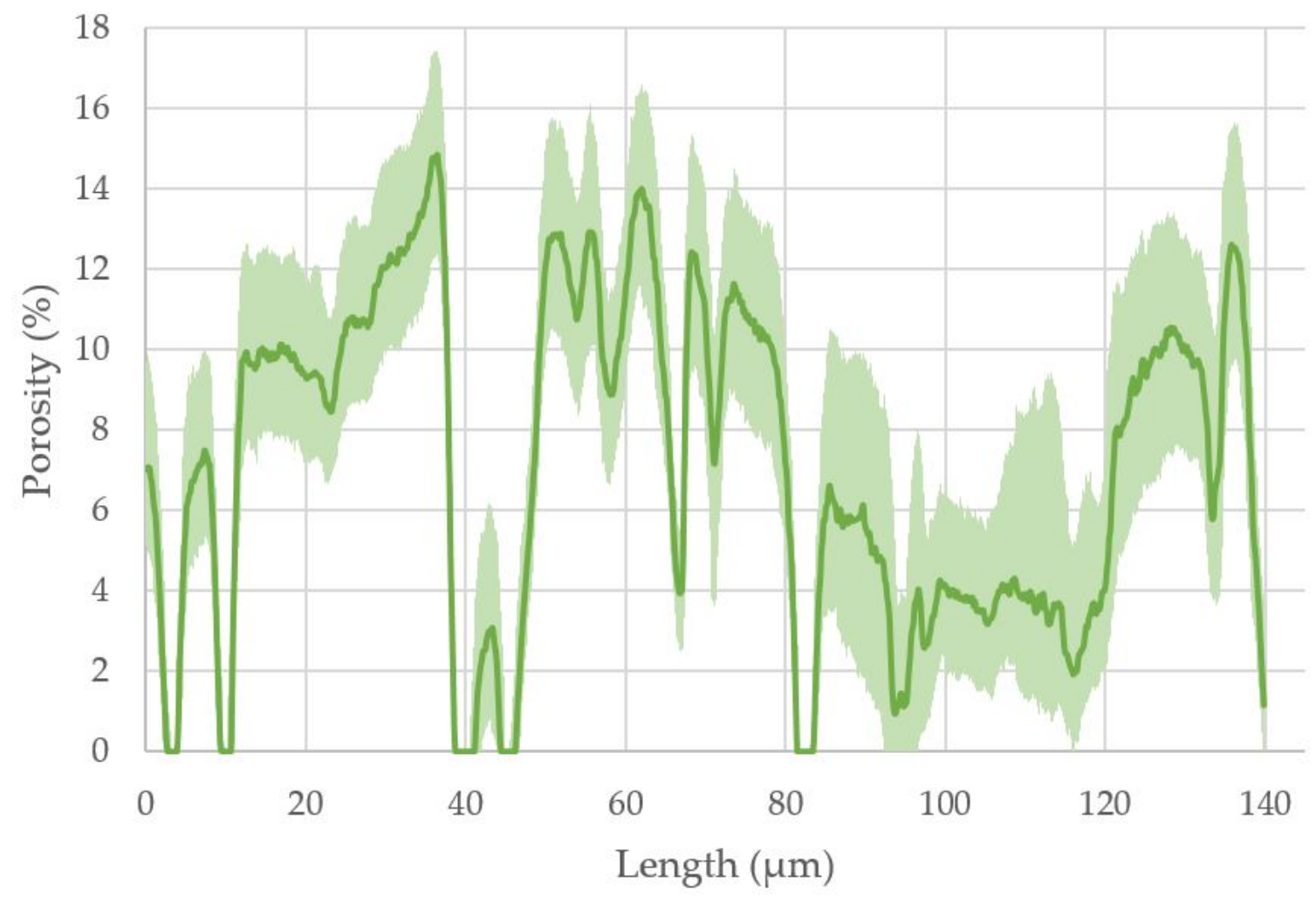

Figure 5. Porosity content along fibre "a" measured for the median threshold value and displaying the upper and lower limit corresponding to the limits of the chosen threshold range.

\subsection{Atomic Force Microscopy}

The flax fibres were dried for $2 \mathrm{~h}$ in an oven at $60{ }^{\circ} \mathrm{C}$ and glued at the extremities of a paper frame. Then, they were embedded in a low viscosity resin (epoxy resin agar low viscosity resin (LV); Agar scientific; UK) and stored in an oven overnight at $60{ }^{\circ} \mathrm{C}$ for the final polymerization. The resulting sample was cut transversally to the fibres using an ultramicrotome (Leica EM UC7, Leica Microsystems SAS, Nanterre, France) equipped with diamond knives (Histo and Ultra, Diatome, Nidau, Switzerland) in order to get a mirroring surface. Peak-Force Quantitative Nano-Mechanical property mapping (PF-QNM) was performed on a multimode 8 atomic force microscope (Bruker) equipped with an RTESPA-525 probe (Bruker AFM Probes, Camarillo, CA, USA). A relative method was used to calibrate the tip and the spring constant was calculated using the Sader method (sadermethod.org/). The spring constant ranged between 105 and $163 \mathrm{~N} / \mathrm{m}$, the resonance frequency was between 519 and $528 \mathrm{kHz}$ and the tip radius between 25 and $55 \mathrm{~nm}$. Moreover, the peak force set-point was $200 \mathrm{nN}$. A detailed protocol can be found in [22]. Images were processed using Gwyddion software (gwyddion.net [23]).

\subsection{Optical Microscopy}

Optical images were obtained using a microscope (Leitz DMRB, Leica Microsystems, Nanterre, France) equipped with a Hamamatsu digital camera (C11440 ORCA-Flash4.0 LT). Large image scanning was performed thanks to a motorized stage (Marzhauser), allowing a $10 \mathrm{~mm}$ scanning along 30 fibres. Images were acquired with a linearly polarized light and magnifications of $\times 20$ and $\times 40$, leading to a spatial resolution of 166 to $328 \mathrm{~nm}$.

\subsection{Tensile Testing}

Tensile testing experiments were carried out on 30 unitary fibres up to the fracture point in a MTS machine (MTS System, Créteil, France) using a $2 \mathrm{~N}$ load cell and a strain rate of $1 \mathrm{~mm} / \mathrm{min}$. The controlled testing environment was set to $25^{\circ} \mathrm{C}$ and $48 \%$ of relative 
humidity. The fibres were extracted manually and glued on a paper frame with a gauge length of $10 \mathrm{~mm}$. The edges of the paper frame were cut prior to the test.

\subsection{Scanning Electron Microscopy Observations}

Scanning electron microscopy (SEM) was performed on 14 unitary fibres after tensile testing (see Section 2.5) close to the rupture point using a JEOL SEM (JSM-IT500HR). The fibres were placed on a carbon sticker and coated with gold using a sputter coater (Scancoat6) from Edward. Observations were conducted under high vacuum conditions with an acceleration voltage of $3 \mathrm{kV}$ and spatial resolution of 2 to $50 \mathrm{~nm}$ depending on the magnification $(\times 1000$ to $\times 20,000)$.

\section{Results}

\subsection{Transversal View: Atomic Force Microscopy}

Figure 6 shows transversal views of flax fibre bundles obtained by Atomic Force Microscopy (AFM). The topographic mappings reveal fibres of various shapes and sizes (Figure 6a-c), with outlines highlighted in Figure 6a. Mean, extremum values, and related standard deviation of full fibres and corresponding lumen surface areas are estimated by image processing in Table 1. For each of the 11 complete fibres from Figure 6, the porosity $P_{i}$ is then calculated using the following formula:

$$
P_{i}(\%)=100 * \frac{S_{p}}{S_{f}}
$$

where, for each fibre, $S_{P}$ is the surface area corresponding to the lumen and $S_{f}$ the surface area corresponding to the filled fibre (excluding internal porosity). The mean porosity $\mathrm{P}$ and related standard deviation $\sigma$ presented in Table 1 are then calculated from the porosity of each fibre $P_{i}$ using the following formula:

$$
\begin{gathered}
P(\%)=\frac{\sum_{i=1}^{i=11} P_{i}}{11} \\
\sigma=\sqrt{\frac{1}{11} \sum_{i=1}^{i=11}\left(P_{i}-P\right)^{2}}
\end{gathered}
$$

Table 1. Mean and extremum values of fibre and lumen surface areas and related porosity content measured from 11 complete fibres on the topological mappings (Figure 6a-c).

\begin{tabular}{cccc}
\hline & Fibre Surface Area $\left(\mu \mathrm{m}^{2}\right)$ & Lumen Surface Area $\left(\mu \mathrm{m}^{2}\right)$ & Porosity $(\%)$ \\
\hline Mean & $\mathbf{1 2 9}$ & $\mathbf{1 . 1}$ & $\mathbf{1 . 2}$ \\
Standard deviation & 87 & 0.7 & 1.1 \\
Minimum & 23 & $\mathbf{0 . 1}$ & 0.4 \\
Maximum & 307 & 2.4 & 4.3 \\
\hline
\end{tabular}

It reveals discrepancies in fibre surface areas, ranging from 23 to $307 \mu \mathrm{m}^{2}$. The smallest fibres probably represent extremities of fibres consequently to the intrusive mode of growth. The lumen size also varies greatly between fibres from 0.1 to $2.4 \mu \mathrm{m}^{2}$, leading to a porosity content between 0.4 and $4.3 \%$, but it should also be taken into account that the surface preparation carried out by ultramicrotome could have generated a small compression on the fibres and a successive deformation of their native shape. Moreover, it is difficult to obtain fibres perfectly aligned vertically, so the porosity calculated here should be treated with caution and a probable underestimation must be considered, even if the calculated values are well aligned with literature data. 

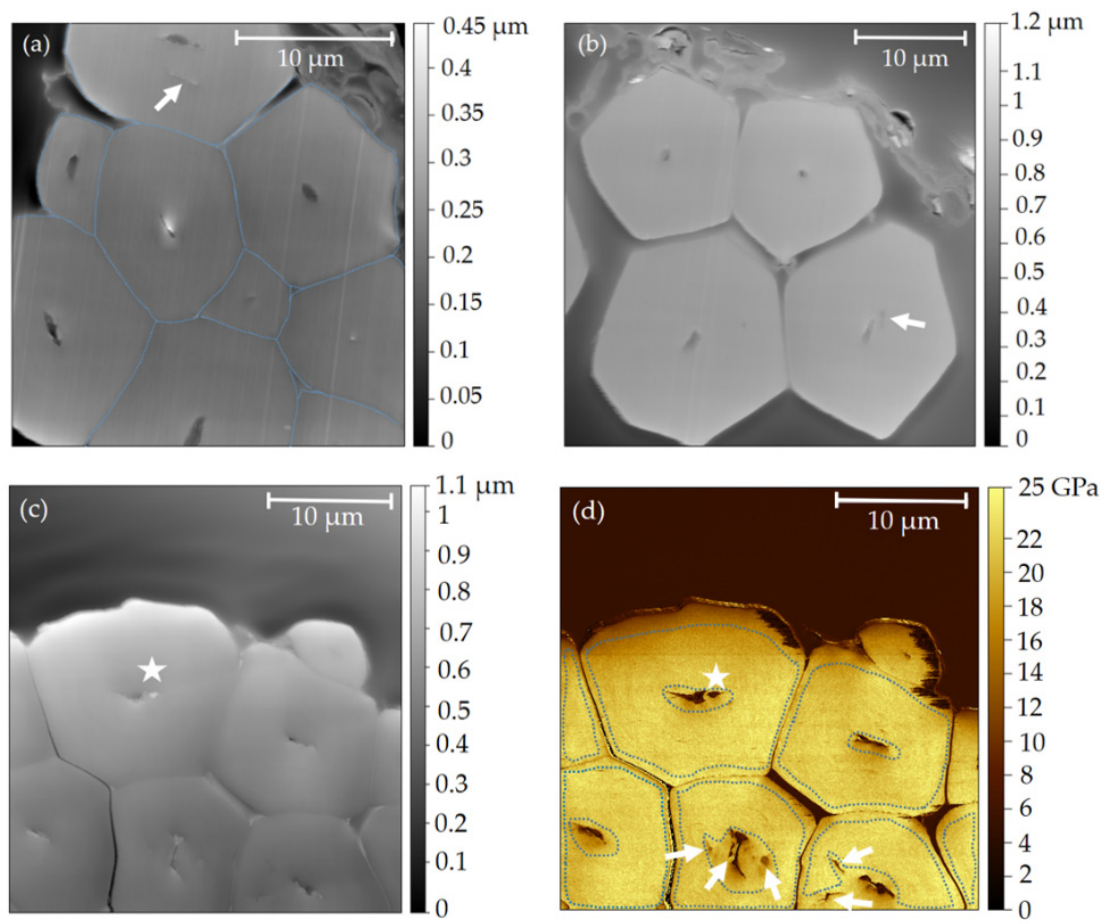

Figure 6. (a-c): Topographical mappings of transversal views of flax fibres obtained by Atomic Force Microscopy (AFM); (d): the related indentation modulus mapping of (c) obtained in PF-QNM mode, with selected masked areas represented by dotted lines. Arrows represent porosities and the star indicates a surface contaminant.

Although at first sight the cell wall marked by a star in Figure $6 c, d$ may appear to have a lumen that could be defined as "double" in indentation modulus mapping, the topography reveals the presence of dust or impurities on the surface. For this reason, both modulus and topography must be analysed. Smaller porosities adjacent to the lumens are highlighted by arrows in Figure 6a,b,d. However, it is difficult to assess the origin of these porosities: they could either be characteristic of a dislocation region or originate from sample preparation artefacts. Finally, acquisitions in PF-QNM mode permit the measurement of the cell wall stiffness. The maturity of the fibres is, therefore, assessed by the presence of thick cell walls and homogeneous stiffness measurements across the cell walls. A mean indentation modulus of $21.5 \pm 1.8 \mathrm{GPa}$ was calculated from the masked areas of Figure 6d, in agreement with previously reported values [24].

\subsection{Longitudinal View: Optical Microscopy}

Optical microscopy reveals the central lumen of flax fibres. Indeed, a central discontinuous line is observed close to the centre of the fibres in Figure 7a,b, visible when observing the opposite side of the fibre too. As highlighted in Figure 7c, the lumen thickness is in the order of magnitude of a few $\mu \mathrm{m}$, and continuous segments in the range of five to a few dozen of $\mu \mathrm{m}$ were observed on several fibres. The lumen thickness of $2 \mu \mathrm{m}$ represents about $13 \%$ of the total fibre diameter at this particular location. However, the lumen as depicted here was not observed for all fibres, possibly due to a size or geometry effect that could be related to differences of maturity. Indeed, the pixel size of $166 \mathrm{~nm}$ might reveal only the more prominent central porosities, as $85 \%$ of the flax fibres lumen content were depicted as inferior to $1 \%$ by Aslan et al. [12]. Moreover, the cell wall transparency might not always be ensured depending on the cell wall width. Dislocations, corresponding to local disorientations of cellulose microfibrils, are also highlighted by arrows in Figure $7 \mathrm{~b}$. 


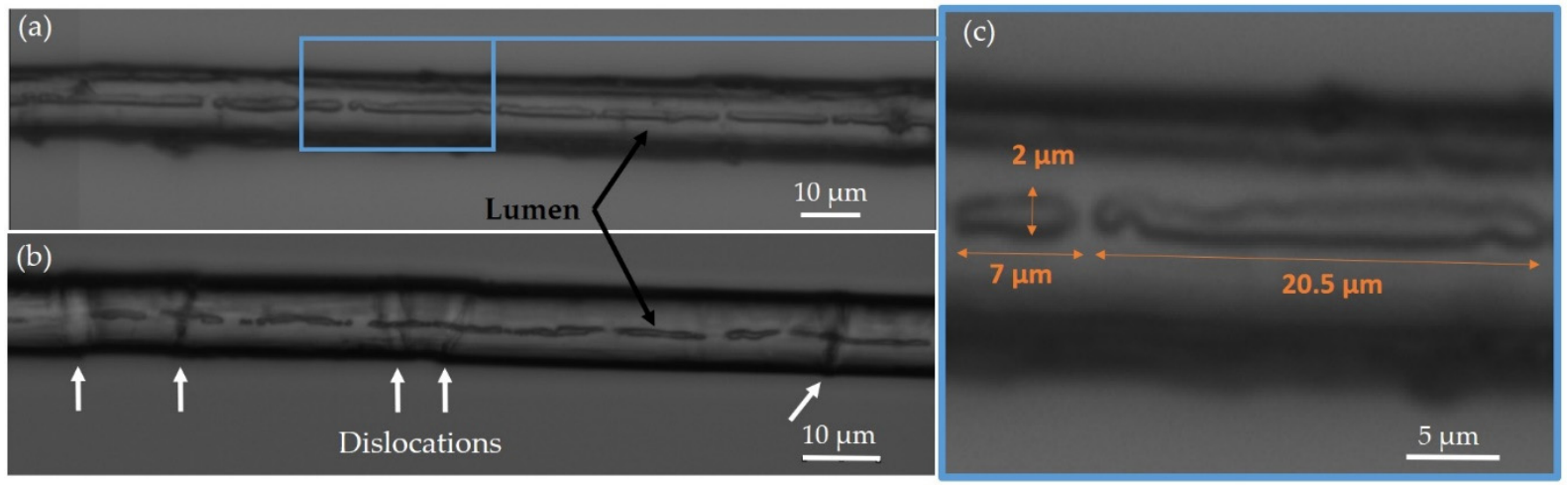

Figure 7. (a,b): Optical observations along two flax fibres focusing on their central lumen segments, which appear as darker areas, and dislocations evidenced by white arrows; (c): enlarged area of the flax fibre represented on (a), with measurements of the lumen segments width and lengths.

\subsection{Volume Reconstruction: X-ray Microtomography}

Volumetric quantification of lumen and fibre geometries was conducted by $\mu \mathrm{CT}$ on two fibres "a" and " $\mathrm{b}$ " and a bundle "c". The bundle is composed of two fibres " $\mathrm{c} 1$ " and "c2", which were artificially dissociated assuming a planar separation to reveal the contribution of each fibre to the total surface area, aspect ratio and porosity content. Variation of crosssectional surface areas and aspect ratio along filled elements (excluding internal porosities) are evidenced in Figures 8 and 9, respectively. Mean fibre external surface areas vary from $54 \mu \mathrm{m}^{2}$ to $194 \mu \mathrm{m}^{2}$ (Table 2) and show fibres of different sizes in agreement with AFM measurements. The aspect ratio is defined as the ratio between the major and minor axis of the particle's fitted ellipse. The mean aspect ratio is around 1.2 and relatively constant along fibres "b", "c1" and "c2". However, fibre "a" is further from a circular idealization with a mean aspect ratio of 1.48 and a higher standard deviation than fibres " $\mathrm{b}$ ", "c1" and "c2", highlighting variations along its length (Figure 9). The aspect ratio of 2.18 for the bundle " $\mathrm{c}$ " validates an elliptical shape formed by the two constituting fibres. The porosity content of each fibre cross-section is defined as follows:

$$
\text { porosity }(\%)=100 * \frac{\sum S_{p}}{\sum S_{f}}
$$

where for each cross-section, $S_{p}$ is the pixels corresponding to porosity and $S_{f}$ the pixels corresponding to the filled fibre. At a macroscopic scale, the mean porosity is calculated as the average value of the cross-sectional porosities along the fibre. As a result, significant discrepancies between fibres are found (Table 1). Indeed, fibres "a" and " $b$ " exhibit a mean porosity content of 7.2 and $2.6 \%$, respectively. Moreover, Figure 10 shows that the porosity content along fibres " $a$ " and " $b$ " varies greatly. Indeed, all fibres present porosity content close to zero at a few points along the scanned length, indicating a narrowed lumen at some areas and intricate shape. The narrowed areas of the lumen are further evidenced on $3 \mathrm{D}$ views of the lumens and fibre longitudinal views extracted from $\mu \mathrm{CT}$ data in Figure 10. In these particular areas, the lumen is under the detection limit allowed by the $150 \mathrm{~nm}$ voxel resolution but might still exist. The bundle " $\mathrm{c}$ " exhibits a mean porosity content of $1.3 \%$, with variations along its length evidenced in Figure 11c and in the video from the Supplementary Data S1, representing the grey-scale transversal views along the bundle c obtained after $\mu \mathrm{CT}$ reconstruction. The contribution of each constitutive fibre to the overall porosity is unequal, coming mostly from fibre " $\mathrm{c} 1$ ", which represent a mean porosity of $1.9 \%$ (Figure $11 \mathrm{a}, \mathrm{c}$ ). The lumen of fibre " $\mathrm{c} 2$ " is under the detection limit along most of the fibres apart from a few particular locations where it raises to more than $6 \%$ of the total fibre surface area (Figure $11 \mathrm{~b}, \mathrm{c})$. These particular areas are further investigated on grey-scale longitudinal cross-sections at increasing depths in Figure 11d-f. It reveals the enlargement along the lumen of fibre "c2" at these locations, and narrowing effects on the neighbouring 
fibre "c1". Porosities adjacent to the lumen are also highlighted on fibre "c1", possibly corresponding to a delamination between flax fibre sublayers. Such lumen disruptions and additional porosities could result from an external stress such as the compression of the cell walls leading to the creation of a defect.

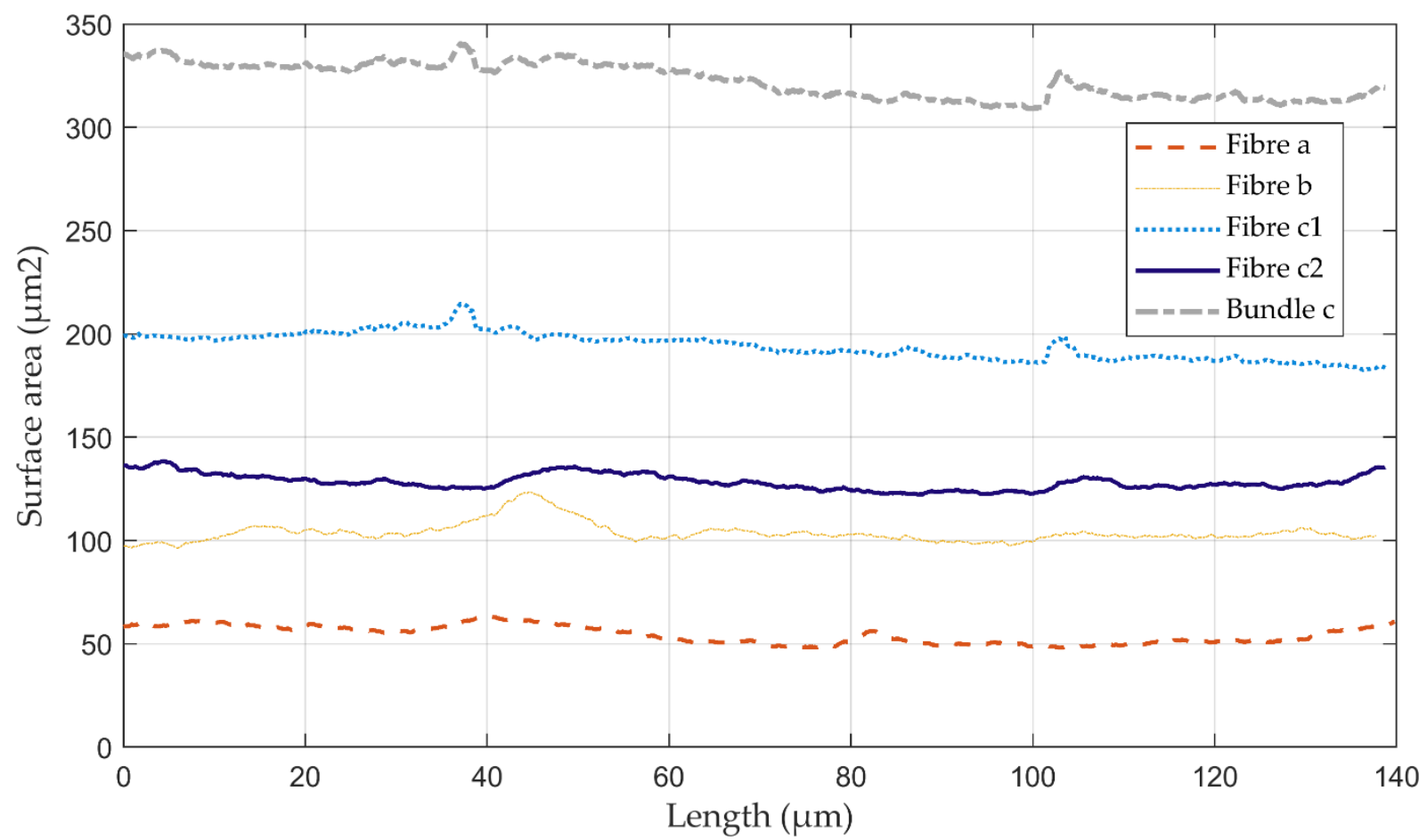

Figure 8. Evolution of the external surface area along two flax fibres "a" and " $b$ " and a bundle "c" composed of two fibres "c1" and "c2", calculated from X-ray microtomography data.

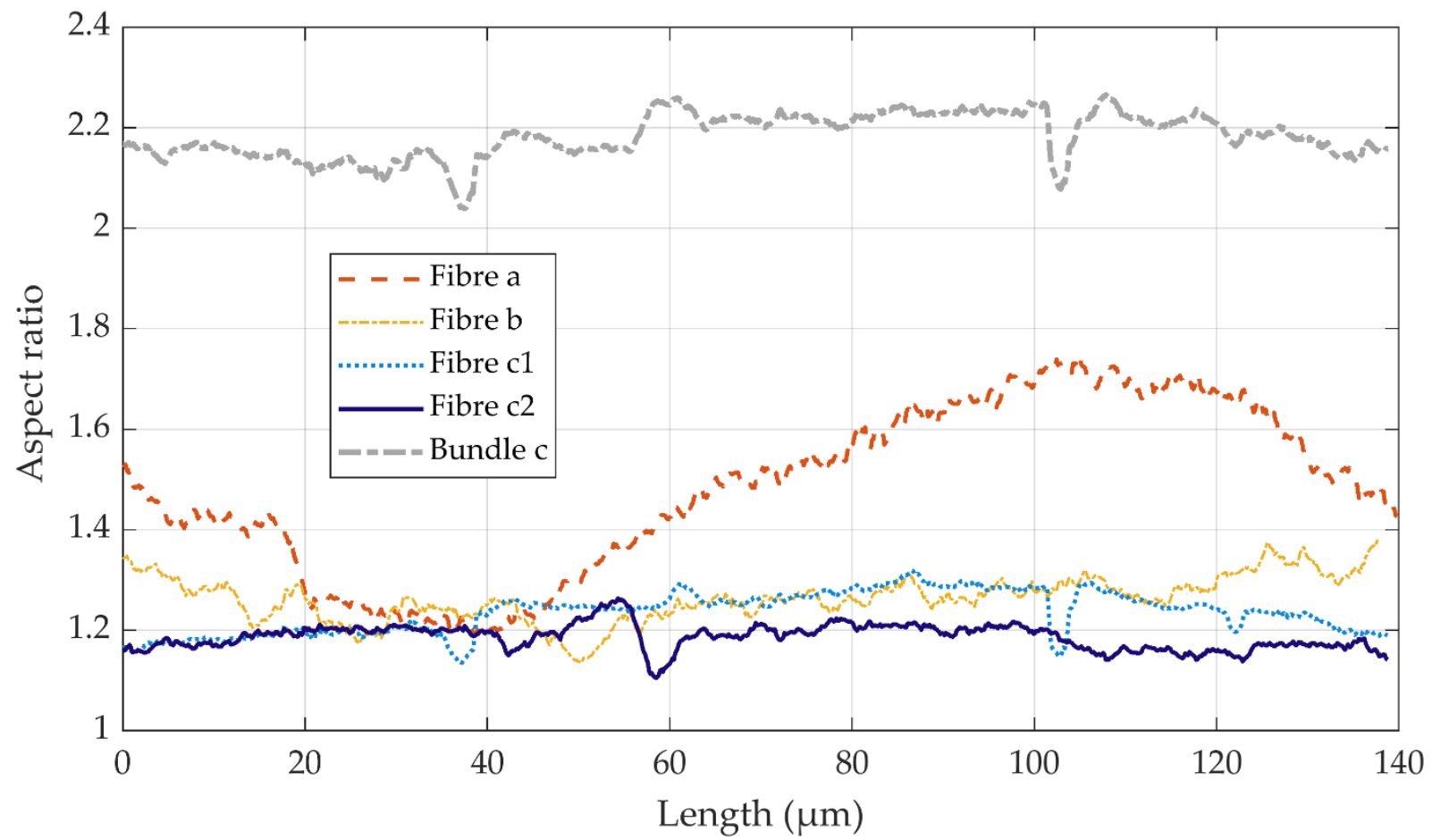

Figure 9. Evolution of the aspect ratio along two flax fibres "a" and " $b$ " and a bundle "c" composed of two fibres "c1" and "c2", measured from X-ray microtomography data. 
Table 2. Aspect ratio, surface area and porosity content of two flax fibres "a" and " $b$ " and a bundle " $c$ " composed of two fibres " $c 1$ " and " $c 2$ " obtained from $\mu$-CT data, with $\mu$ the mean value and $\sigma$ the standard deviation. Last column represents the mean values of the fibres "a", "b", "c1" and "c2".

\begin{tabular}{|c|c|c|c|c|c|c|c|}
\hline \multicolumn{2}{|c|}{ Flax Sample } & Fibre a & Fibre b & Bundle c & Fibre $c_{1}$ & Fibre $c_{2}$ & Mean \\
\hline \multirow{2}{*}{ Aspect ratio } & $\mu$ & 1.48 & 1.26 & 2.18 & 1.24 & 1.19 & 1.29 \\
\hline & $\sigma$ & 0.17 & 0.04 & 0.04 & 0.04 & 0.02 & 0.11 \\
\hline \multirow{2}{*}{$\begin{array}{l}\text { Surface area } \\
\qquad\left(\mu \mathrm{m}^{2}\right)\end{array}$} & $\mu$ & 54.3 & 103.8 & 322.5 & 194.2 & 128.3 & 120.2 \\
\hline & $\sigma$ & 4.3 & 4.9 & 8.4 & 6.4 & 3.7 & 50.4 \\
\hline \multirow{2}{*}{ Porosity (\%) } & $\mu$ & 7.2 & 2.6 & 1.3 & 1.9 & 0.4 & 3.0 \\
\hline & $\sigma$ & 4.0 & 1.1 & 0.7 & 0.9 & 1.0 & 2.5 \\
\hline
\end{tabular}
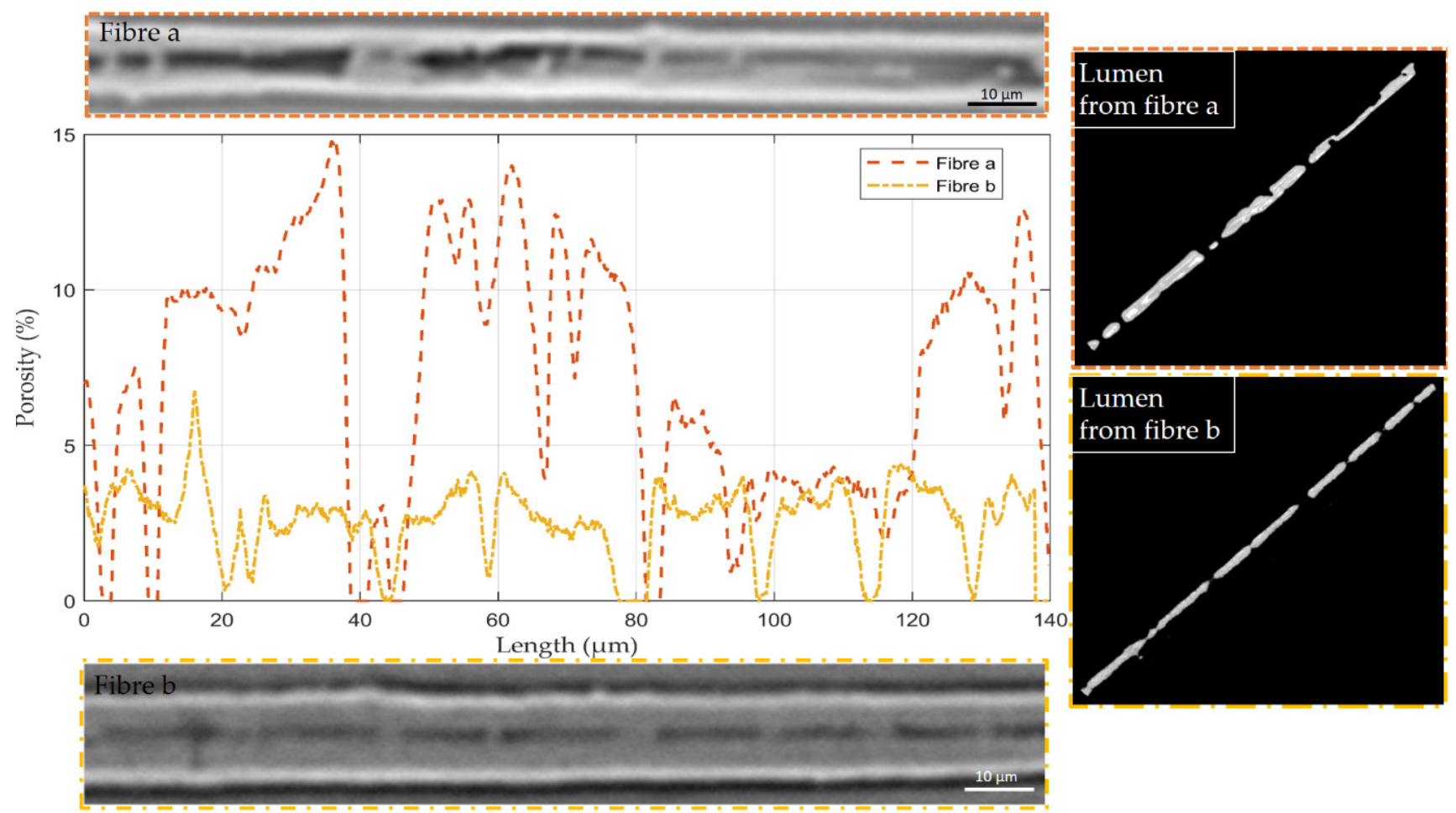

Figure 10. Porosity profile along two flax fibres " $a$ " and " $b$ ", corresponding longitudinal cross-sections of the fibres and 3D views revealing the internal lumen after image processing (right).

\subsection{Lumen, Defects and Fibre Failure}

In Figure 12c, failure of a fibre by tensile testing and SEM observation reveals what could be the intricate shape of the central lumen. The internal part of the lumen is smooth compared to the neighbouring damaged cell walls revealing aligned cellulose microfibrils (Figure 12d-f). Widths in the order of magnitude of $1.7 \mu \mathrm{m}$ are reported for the lumen, with narrowings in the fibre axis direction comparable to a bottleneck effect. Moreover, a second longitudinal cavity parallel to the lumen is depicted in Figure 12b. We believe it could be a result of the falling apart of cellulose microfibrils upon tensile failure. However, without crosschecking with other experimental techniques it is difficult to distinguish the original lumen shape from the result of damage, and such lumen geometry was observed once out of 14 fibres. A misalignment of cellulose microfibrils, also known as dislocation, is observed in Figure 12a close to the damage initiation or final step prior complete fibre failure. Moreover, the tensile properties of the observed fibre lie within the range of flax fibre properties usually reported in the literature [24], for which a strain at break of $2.3 \%$, a strength of $959 \mathrm{MPa}$ and a Young's modulus of $44.2 \mathrm{GPa}$ are obtained. 

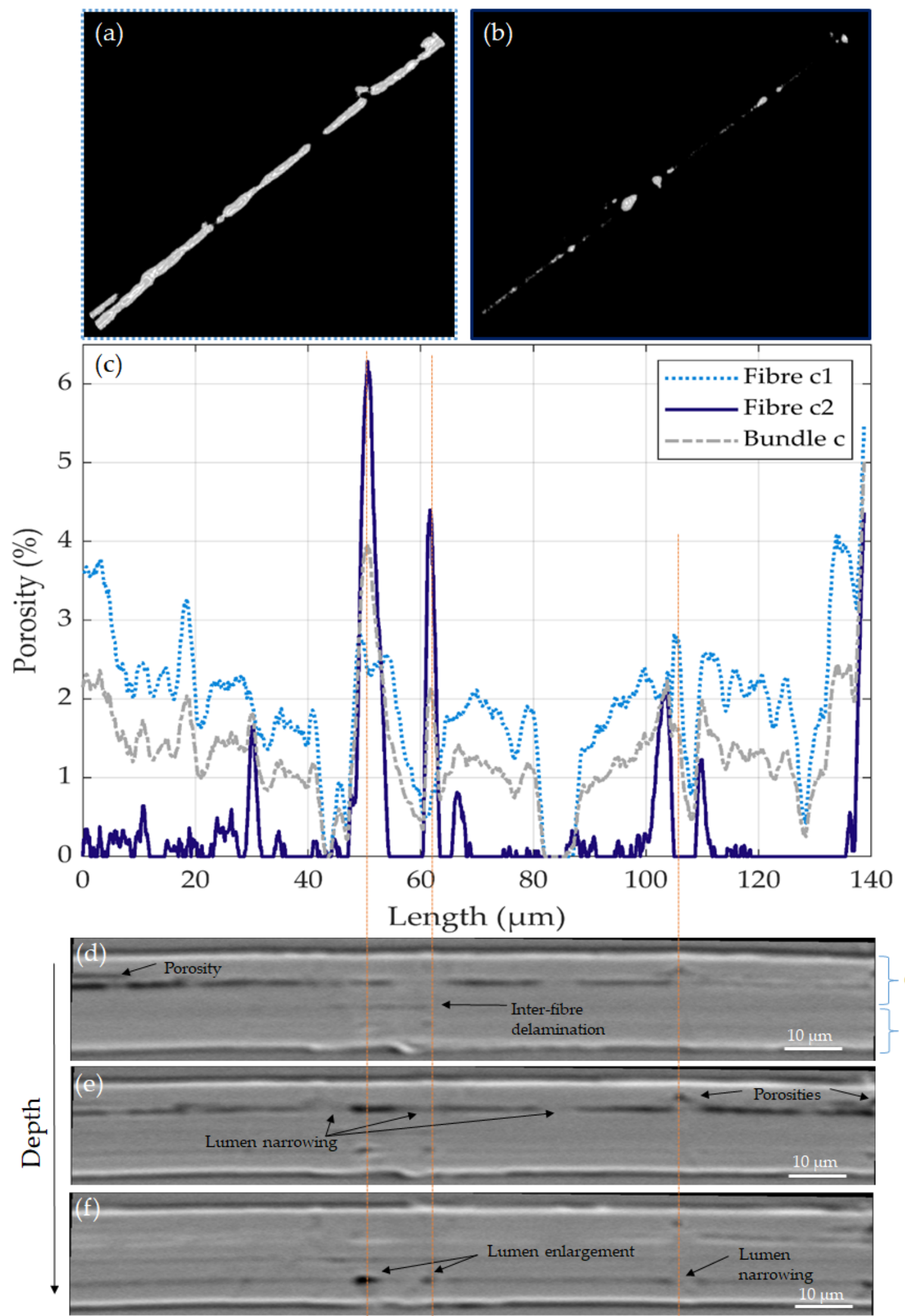

Figure 11. $(\mathbf{a}, \mathbf{b})$ : $3 \mathrm{D}$ views of the internal porosity of fibres " $c 1$ " and "c2" respectively; (c) porosity profile along bundle " $c$ " and the contribution of its two constitutive flax fibres " $c 1$ " and " $c 2$ "; $(\mathbf{d}-\mathbf{f})$ : longitudinal bundle cross-sections at increasing depths; from $\mu \mathrm{CT}$ data. 

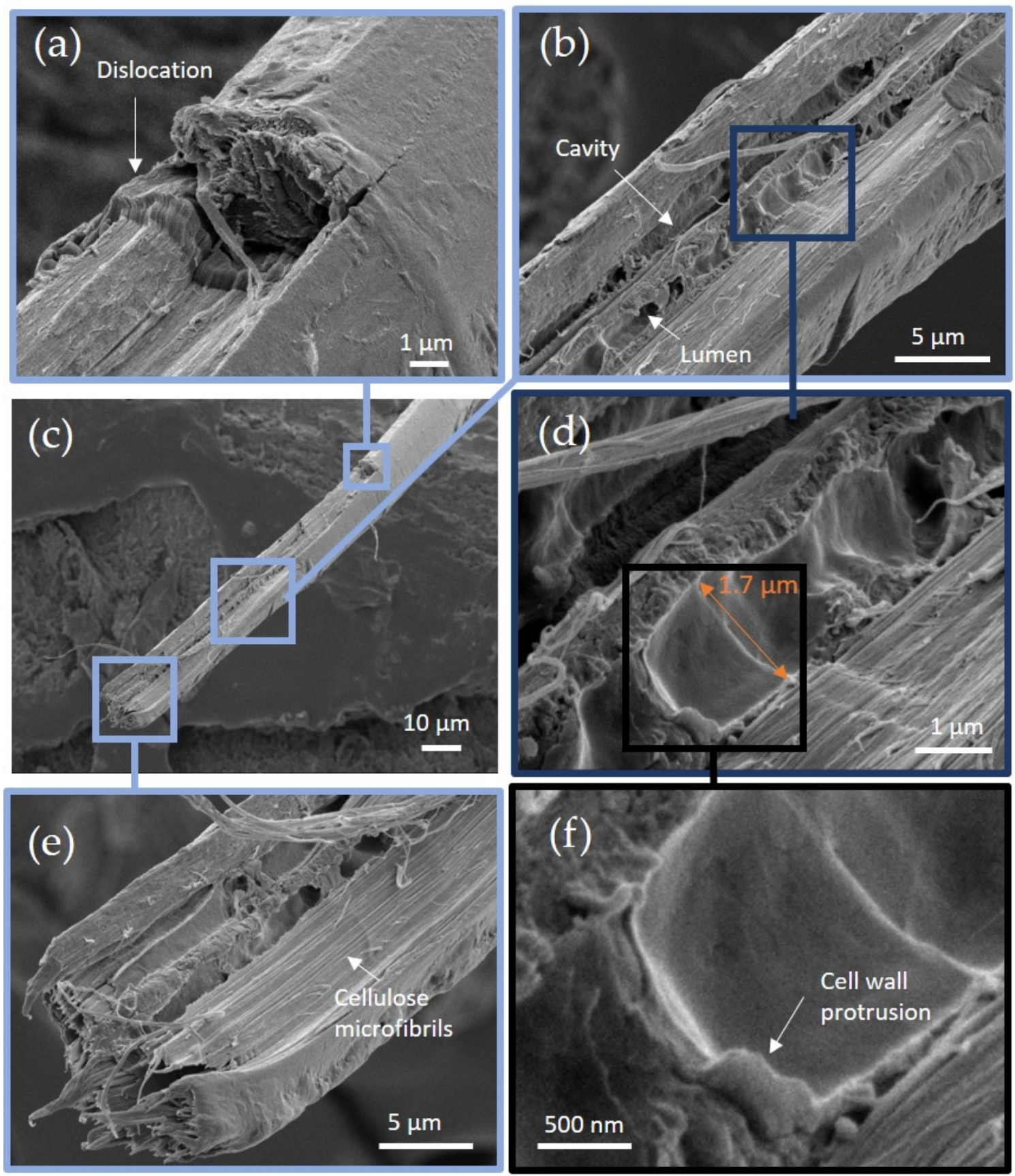

Figure 12. SEM observation of the fracture surface of a flax fibre after tensile testing (c) and focus on different areas. (a) near a dislocation, (b) along the cavity, (c) outer view up to the fractured edge (d) close view at the damaged area, (e) zoom on microfibrils arrangement, (f) close view at the cell wall protrusion.

\section{Discussion}

The literature reports few quantifications of plant fibre porosity. An attempt to benchmark the results obtained for flax in this study by $\mu \mathrm{CT}$ with other techniques and botanical origin is presented in Figure 1. Plant fibres exhibit a wide range of lumen size depending on the variety, from $1.5 \%$ for bamboo to $45 \%$ for abaca. Among them, mean values of flax lumen from 1.6 to $6.8 \%$ were reported, based on transversal cuts and optical observations. The values of porosities extracted from tomographic images in this study, from 0.4 to $7.2 \%$ with a mean value of $3 \pm 2.5 \%$ (Table 2) are, therefore, in the same range as literature data.

The inter-fibre variability was further highlighted by AFM and $\mu \mathrm{CT}$ measurements (Tables 1 and 2). Differences in surface areas of the cell wall could be partly explained by 
the fibre intrusive mode of growth. Indeed, it has been shown that flax cells do not elongate at the same rate as their neighbours and have to force their way between other cells in order to reach their final length [25]. To do so, both fibre extremities become knee-like shaped, leading to thinner extremities, visible in Figure 6a. Therefore, small surface areas obtained on a transversal cut of bundles of fibres could correspond to fibres cut close to their extremities. Moreover, thickening of the cell wall starts from the snap point region first in the outer fibres and later in the fibres located in the centre of the stem [26]. Differences of maturity at harvest may, therefore, explain variabilities in cell wall thicknesses and resulting lumen sizes. The influence of climate and location along the stem on the fibre filling has also been studied extensively [27]. However, it should only play a minor role in our study focusing on fibres extracted from the middle of the stems of a single variety and growth condition.

The intricate shape of lumen along a fibre was revealed by both optical microscopy, SEM and $\mu$-CT. Indeed, optical microscopy highlighted narrowed areas along the lumen (Figure 7a) with continuous segments sizes in the same order of magnitude, a few dozens of microns, as evidenced by $\mu \mathrm{CT}$ (Figures 10 and 11). This result is in agreement with discrepancies of lumen size observed along a hemp fibre by Beaugrand et al. [6]. Based on these converging observations, we propose a novel representation of the flax fibre lumen in Figure 13a.
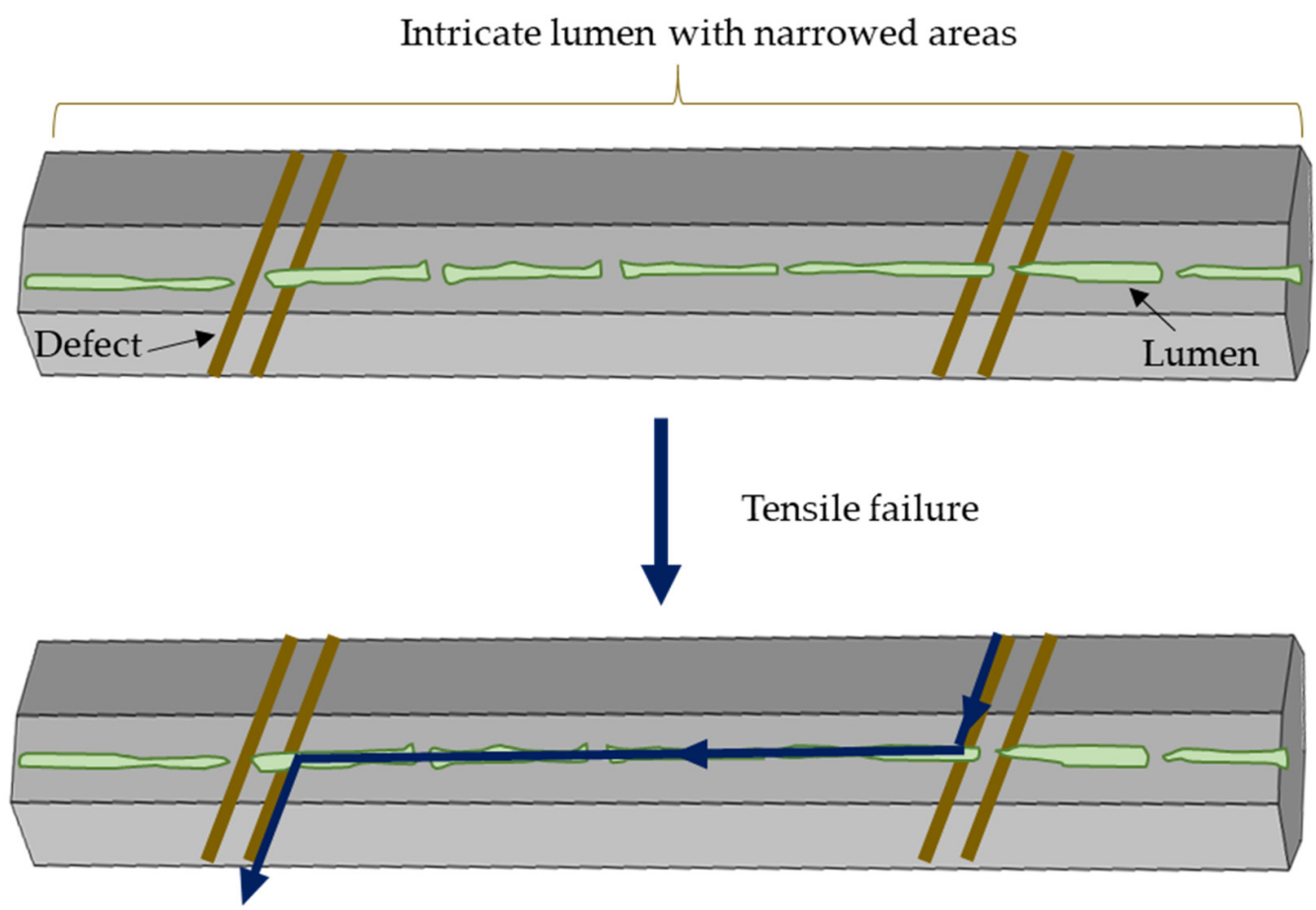

Figure 13. (a) Schematic representation of the intricate shape of flax fibre lumen and (b) proposed scenario for fibre tensile failure.

These variabilities may originate from different stages of the plant cell life, the most likely being the cell wall thickening or the final death of the cell and following extraction processes. For such long cells, a local inhomogeneous repartition of the cellular material along fibres, for instance the presence of numerous nuclei in a flax cell [28], might induce heterogeneities of the dried off material of protoplasm, thus, influencing the shape of the lumen. The process of protoplasm degradation and drying off could be a key point in the shape of the final lumen. Ageeva et al. [29] described the key stages of fibre death including a gradual degradation of cytoplasm starting already during cell wall thickening followed by the rupture of tonoplast. However, unlike the growth of fibres, which has already been studied extensively, the formation of lumen has not been described in detail 
in the literature. Finally, a bottleneck effect and increase in lumen diameter was observed by Ibragimova et al. [30] on the pulling side of flax stems subjected to gravitropism. The lumen was even occluded at some areas concomitantly to callose deposition. This (1-3)- $\beta$ D-glucan is composed of glucose units and involved in plant stress defence mechanisms. Contrary to our study, the "sausage-like" irregular shape was observed along the cell external boundaries and not only affected the lumen. However, it highlights the ability of plant fibres to change their shape in response to external stimuli.

Moreover, the fibres observed in this study and used as composite reinforcements underwent several processing stages such as drying, retting, and mechanical extraction from the stem. These processes might influence the lumen shape and present observations cannot be attributed to the fibre cell state in-planta but rather to post-mortem changes. Indeed, the central vacuole present in the living cell [31], which is mainly filled with water, might shrink upon drying of the fibre and thus change the fibre structure. Upon drying, the radial dimensions of the fibre and its internal lumen might also change and particular attention should be paid to the role of the biochemical components of the cell wall [32]. In particular, pectic substances such as homogalacturonans and rhamnogalacturonan-I (RG-I) [33] are polyanions, the main components interacting with water in the cell wall [34]. Shrinkage of the fibre was already reported in planta due to progressive drying, depending on the growth conditions, varieties, lignin content and location within the stem $[35,36]$. An initial water content of respectively 19.0 and 9.1\% was assessed by Gibaud et al. for the bottom and middle part of green stems, which stabilized around $6.15 \%$ upon atmosphere drying (at $23{ }^{\circ} \mathrm{C}$ and 50\% relative humidity) in both cases [37]. Furthermore, the authors reported fibre shrinkage upon drying, with a decrease of diameter ranging from 20 to 30\%, between green and dry fibres from the lower part of the stem, whereas a decrease of $10 \%$ was reported for fibres in the middle of the stem. Moreover, several authors highlighted external dimensional changes of plant fibres subjected to different environmental conditions after cell death and fibre extraction. X-ray tomography conducted on a single wood fibre by Joffre et al. [38] showed dimensional changes when increasing the ambient relative humidity from $47 \%$ to $80 \%$, but without focusing on the lumen shape. Garat et al. [8] determined a decrease of the form factor of flax bundles under increasing relative humidity conditions. In these cases, the fibres might swell in an anisotropic way partly to recover their in-planta rehydrated and more circular state. It seems likely that these external changes of diameter and shape might also affect the internal lumen and be responsible for the flat lumen shapes evidenced by X-ray tomography (Figure 10-fibre a). Upon the next extraction step, enzymes involved in the retting stage act primarily on pectins [39] and this may also modify the overall fibre and lumen shape. Moreover, mechanical extraction of fibres from the stem and resulting defect creations might disrupt the lumen channel and explain the narrowing effects observed in Figures 10 and 11. X-ray tomography conducted at the composite scale also revealed flax lumen discontinuities caused by barrel-shaped defects, also known as nodes [40]. Disruption of lumen was further reported close to nodes of several bast fibres by SEM observations conducted by Wang et al. [41]. In our study, porosities adjacent to the lumen of fibre c1 were also highlighted in Figure 11d-f. Such additional porosities could result from an external stress such as the compression of the cell walls leading to the creation of a defect. Defect creation is arguably occurring during the growth of the plant or more likely from extraction processes [42], the fibre bundles being less protected from deformation than in a stem. Similar cavities have been reported by Zhang et al. [5] close to nodal markings of flax fibres using SEM with focused ion beam. Porosities might also result from sublayer delamination [4]. However, it is difficult to localize these porosities within the fibre sublayers from $X$-ray tomography data because of insufficient contrast between sublayers of close chemical composition and densities. Additional experimental work would be required to better understand the contribution of the different mechanisms involved in the final shaping of the lumen.

Finally, the possible implication of lumen in the failure of flax fibres was hypothesized in Figure 13. Indeed, in the proposed scenario represented in Figure 13b, the initial or final 
stage of failure seems to occur on a dislocation (Figure 12a) during loading. The transversal failure propagates through the central lumen, deviating the initial transverse crack to a longitudinal one, and probably connecting a second dislocation at the other extremity leading to final transverse failure. This scenario of "bridging" has already been observed by Beaugrand et al. [6] for hemp at the bundle scale. They highlighted the delaying of rupture thanks to the dissipation of energy caused by the lumen deviation. The complementary role of transverse and longitudinal crack propagation in the failure of flax fibres was also highlighted by Aslan et al. [12], without relating longitudinal cracks to the lumen, and at the composite scale by Madsen et al. [43]. The interaction between defects and lumen could be explained by the stress concentrations induced by both geometrical inhomogeneities. They will be, therefore, concomitant to drive the failure of the fibre, depending on the lumen shape and on the dislocation severity. Since fibre failure seems to be the most critical damage mechanism at the composite scale [40], it is of interest to understand the mechanisms leading to its failure in order to prevent them and achieve better tailoring of biocomposites. In particular, deepening of the proposed scenario will be conducted in the near future by in situ tensile testing and high-resolution X-ray tomography. Additional 3D image correlation is also a promising complement to assess the local strain fields.

\section{Conclusions}

A novel representation of the intricate shape of the lumen was proposed in this study by means of complementary characterization techniques on flax fibres, leading to converging results. Indeed, the lumen was found of heterogeneous size along the length of the fibre, with areas where the lumen could not be detected at the spatial resolution achieved in this study. The lumen porosity content was quantified on several fibres between 0.4 to $7.2 \%$ thanks to high-resolution X-ray microtomography. The inter and intra-fibre lumen variabilities observed might be correlated to the cell-wall thickening and cell death but also influenced by post mortem processes such as the drying, retting, and mechanical extraction of the fibres. Deciphering their origin would require further investigations and particular attention should be drawn to the lumen deformations induced by defects along fibres. Finally, the combined actions of lumen and defects in driving the failure of the fibre were underlined by SEM observation on fracture surfaces after tensile testing. As future research directions, the proposed scenario will first be confirmed by means of in-situ mechanical testing including X-ray microtomography performed at high resolution and low acquisition times thanks to Synchrotron sources. The results will then be implemented in a finite element model. In particular, the role of smaller internal porosities such as cavities and sublayer delamination in the failure behaviour of flax fibres will also be studied more extensively in the future.

Supplementary Materials: The following are available online at https:/ /www.mdpi.com/article/10 $.3390 /$ fib 9040024 /s1, Video S1: Grey-scale transversal views along the bundle c composed of two fibres $\mathrm{c} 1$ and $\mathrm{c} 2$, obtained after $\mu \mathrm{CT}$ reconstruction.

Author Contributions: Conceptualization, E.R., J.B. and S.G.; validation, A.B., E.R., J.B., S.G. and T.G.; formal analysis, A.K., E.R., S.G.; investigation, A.K., A.M. (Anthony Magueresse), A.M. (Alessia Melelli), E.R., and S.D.; resources, F.C., A.B., H.D.; writing—original draft preparation, E.R.; writingreview and editing, F.C., A.B., A.M. (Alessia Melelli), E.R., H.D., J.B., S.D., S.G., T.G.; visualization, E.R., J.B., S.G.; supervision, J.B., S.G.; project administration, J.B., S.G.; funding acquisition, A.B., J.B. All authors have read and agreed to the published version of the manuscript.

Funding: This research was funded by the INTERREG VA FCE Program, FLOWER project, Grant Number 23.

Institutional Review Board Statement: Not applicable.

Informed Consent Statement: Not applicable.

Data Availability Statement: Data supporting the findings of this study are available on simple request from the corresponding author. 
Acknowledgments: The authors would like to thank David Legland for his advice on image processing techniques.

Conflicts of Interest: The authors declare no conflict of interest. The funders had no role in the design of the study; in the collection, analyses, or interpretation of data; in the writing of the manuscript, or in the decision to publish the results.

\section{References}

1. Charlet, K.; Jernot, J.; Eve, S.; Gomina, M.; Bréard, J. Multi-scale morphological characterisation of flax: From the stem to the fibrils. Carbohydr. Polym. 2010, 82, 54-61. [CrossRef]

2. Madsen, B.; Gamstedt, E.K. Wood versus Plant Fibers: Similarities and Differences in Composite Applications. Adv. Mater. Sci. Eng. 2013, 2013, 1-14. [CrossRef]

3. Thuault, A. Approche Multi-échelle de la Structure et du Comportement Mécanique de la Fibre de lin. Ph.D. Thesis, University of Caen Basse Normandie, Caen, France, 2011.

4. Hernandez-Estrada, A.; Reza, M.; Hughes, M. The Structure of Dislocations in Hemp (Cannabis sativa L.) Fibres and Implications for Mechanical Behaviour. BioResources 2020, 15, 2579-2595.

5. Zhang, H.; Sui, T.; Thygesen, L.G.; O’Brien, P.; Korsunsky, A.M. Multi-modal microscopy characterisation of nodal markings in flax fibre. In Proceedings of the World Congress on Engineering, London, UK, 1-3 July 2015.

6. Beaugrand, J.; Guessasma, S.; Maigret, J.-E. Damage mechanisms in defected natural fibers. Sci. Rep. 2017, 7, 14041. [CrossRef]

7. Guessasma, S.; Beaugrand, J. Damage Kinetics at the Sub-micrometric Scale in Bast Fibers Using Finite Element Simulation and High-Resolution X-Ray Micro-Tomography. Front. Plant Sci. 2019, 10, 194. [CrossRef] [PubMed]

8. Garat, W.; Le Moigne, N.; Corn, S.; Beaugrand, J.; Bergeret, A. Swelling of natural fibre bundles under hygro- and hydrothermal conditions: Determination of hydric expansion coefficients by automated laser scanning. Compos. Part A Appl. Sci. Manuf. 2020, 131, 105803. [CrossRef]

9. Le Duigou, A.; Requile, S.; Beaugrand, J.; Scarpa, F.; Castro, M. Natural fibres actuators for smart bio-inspired hygromorph biocomposites. Smart Mater. Struct. 2017, 26, 125009. [CrossRef]

10. Li, Y.; Ma, H.; Shen, Y.; Li, Q.; Zheng, Z. Effects of resin inside fiber lumen on the mechanical properties of sisal fiber reinforced composites. Compos. Sci. Technol. 2015, 108, 32-40. [CrossRef]

11. Baley, C.; Perrot, Y.; Busnel, F.; Guézénoc, H.; Davies, P. Transverse tensile behaviour of unidirectional plies reinforced with flax fibres. Mater. Lett. 2006, 60, 2984-2987. [CrossRef]

12. Aslan, M.; Chinga-Carrasco, G.; Sørensen, B.F.; Madsen, B. Strength variability of single flax fibres. J. Mater. Sci. 2011, 46, 6344-6354. [CrossRef]

13. Charlet, K.; Jernot, J.-P.; Breard, J.; Gomina, M. Scattering of morphological and mechanical properties of flax fibres. Ind. Crop. Prod. 2010, 32, 220-224. [CrossRef]

14. Liu, K.; Takagi, H.; Osugi, R.; Yang, Z. Effect of lumen size on the effective transverse thermal conductivity of unidirectional natural fiber composites. Compos. Sci. Technol. 2012, 72, 633-639. [CrossRef]

15. Fidelis, M.E.A.; Pereira, T.V.C.; Gomes, O.D.F.M.; Silva, F.D.A.; Filho, R.D.T. The effect of fiber morphology on the tensile strength of natural fibers. J. Mater. Res. Technol. 2013, 2, 149-157. [CrossRef]

16. Schäfer, T.; Honermeier, B. Effect of sowing date and plant density on the cell morphology of hemp (Cannabis sativa L.). Ind. Crop. Prod. 2006, 23, 88-98. [CrossRef]

17. Beaugrand, J.; Nottez, M.; Konnerth, J.; Bourmaud, A. Multi-scale analysis of the structure and mechanical performance of woody hemp core and the dependence on the sampling location. Ind. Crop. Prod. 2014, 60, 193-204. [CrossRef]

18. Charlet, K. Contribution à l'étude de Composites Unidirectionnels Renforcés par des Fibres de lin: Relation Entre la Microstructure de la Fibre et ses Propriétés Mécaniques. Ph.D. Thesis, University of Caen Basse Normandie, Caen, France, 2008.

19. De Rosa, I.M.; Kenny, J.M.; Puglia, D.; Santulli, C.; Sarasini, F. Morphological, thermal and mechanical characterization of okra (Abelmoschus esculentus) fibres as potential reinforcement in polymer composites. Compos. Sci. Technol. 2010, 70, 116-122. [CrossRef]

20. Abbey, B.; Eve, S.; Thuault, A.; Charlet, K.; Korsunsky, A. Synchrotron X-ray tomographic investigation of internal structure of individual flax fibres. In Proceedings of the 6th World Congress of Biomechanics (WCB 2010), Singapore, 1-6 August 2010; pp. 1151-1154.

21. Legland, D.; Arganda-Carreras, I.; Andrey, P. MorphoLibJ: Integrated library and plugins for mathematical morphology with ImageJ. Bioinformatics 2016, 32, 413-3534. [CrossRef]

22. Melelli, A.; Arnould, O.; Beaugrand, J.; Bourmaud, A. The Middle Lamella of Plant Fibers Used as Composite Reinforcement: Investigation by Atomic Force Microscopy. Molecules 2020, 25, 632. [CrossRef]

23. Nečas, D.; Klapetek, P. Gwyddion: An open-source software for SPM data analysis. Open Phys. 2012, 10. [CrossRef]

24. Bourmaud, A.; Beaugrand, J.; Shah, D.U.; Placet, V.; Baley, C. Towards the design of high-performance plant fibre composites. Prog. Mater. Sci. 2018, 97, 347-408. [CrossRef]

25. Ageeva, M.V.; Petrovská, B.; Kieft, H.; Sal'Nikov, V.V.; Snegireva, A.V.; Van Dam, J.E.G.; Van Veenendaal, W.L.H.; Emons, A.M.C.; Gorshkova, T.A.; Van Lammeren, A.A.M. Intrusive growth of flax phloem fibers is of intercalary type. Planta 2005, 222, 565-574. [CrossRef] [PubMed] 
26. Gorshkova, T.A.; Sal'Nikov, V.V.; Chemikosova, S.B.; Ageeva, M.V.; Pavlencheva, N.V.; Van Dam, J.E. The snap point: A transition point in Linum usitatissimum bast fiber development. Ind. Crop. Prod. 2003, 18, 213-221. [CrossRef]

27. Bourmaud, A.; Gibaud, M.; Lefeuvre, A.; Morvan, C.; Baley, C. Influence of the morphology characters of the stem on the lodging resistance of Marylin flax. Ind. Crop. Prod. 2015, 66, 27-37. [CrossRef]

28. Snegireva, A.V.; Ageeva, M.V.; Amenitskii, S.I.; Chernova, T.E.; Ebskamp, M.; Gorshkova, T.A. Intrusive growth of sclerenchyma fibers. Russ. J. Plant Physiol. 2010, 57, 342-355. [CrossRef]

29. Ageeva, M.V.; Chernova, T.E.; Gorshkova, T.A. Processes of protoplast senescence and death in flax fibers: An ultrastructural analysis. Russ. J. Dev. Biol. 2012, 43, 94-100. [CrossRef]

30. Ibragimova, N.N.; Ageeva, M.V.; Gorshkova, T.A. Development of gravitropic response: Unusual behavior of flax phloem G-fibers. Protoplasma 2016, 254, 749-762. [CrossRef]

31. Schmid, R.; Evert, R.F. (Franklin) Esau's Plant Anatomy: Meristems, Cells, and Tissues of the Plant Body: Their Structure, Function, and Development. TAXON 2008, 57, 678. [CrossRef]

32. Pejic, B.M.; Kostic, M.M.; Skundric, P.D.; Praskalo, J.Z. The effects of hemicelluloses and lignin removal on water uptake behavior of hemp fibers. Bioresour. Technol. 2008, 99, 7152-7159. [CrossRef]

33. Petrova, A.A.; Kozlova, L.V.; Gaifullina, I.Z.; Ananchenko, B.A.; Martinson, E.A.; Mikshina, P.V.; Gorshkova, T.A. AFM analysis reveals polymorphism of purified flax rhamnogalacturonans I of distinct functional types. Carbohydr. Polym. 2019, 216, 238-246. [CrossRef]

34. Baley, C.; Morvan, C.; Grohens, Y. Influence of the Absorbed Water on the Tensile Strength of Flax Fibers. Macromol. Symp. 2005, 222, 195-202. [CrossRef]

35. Morvan, C.; Andème-Onzighi, C.; Girault, R.; Himmelsbach, D.S.; Driouich, A.; Akin, D.E. Building flax fibres: More than one brick in the walls. Plant Physiol. Biochem. 2003, 41, 935-944. [CrossRef]

36. Milthorpe, F.L. Fibre Development of Flax in Relation to Water Supply and Light IntensityI. Ann. Bot. 1945, 9, 31-53. [CrossRef]

37. Gibaud, M.; Bourmaud, A.; Baley, C. Understanding the lodging stability of green flax stems; The importance of morphology and fibre stiffness. Biosyst. Eng. 2015, 137, 9-21. [CrossRef]

38. Joffre, T.; Isaksson, P.; Dumont, P.J.J.; du Roscoat, S.R.; Sticko, S.; Orgéas, L.; Gamstedt, E.K. A Method to Measure Moisture Induced Swelling Properties of a Single Wood Cell. Exp. Mech. 2016, 56, 723-733. [CrossRef]

39. Akin, D.E. Linen Most Useful: Perspectives on Structure, Chemistry, and Enzymes for Retting Flax. ISRN Biotechnol. 2013, 2013, 1-23. [CrossRef] [PubMed]

40. Rask, M.; Madsen, B.; Sørensen, B.F.; Fife, J.L.; Martyniuk, K.; Lauridsen, E.M. In situ observations of microscale damage evolution in unidirectional natural fibre composites. Compos. Part A Appl. Sci. Manuf. 2012, 43, 1639-1649. [CrossRef]

41. Wang, H.M.; Wang, X. Surface morphologies and internal fine structures of bast fibers. Fibers Polym. 2005, 6, 6-12. [CrossRef]

42. Bos, H.L.; Oever, M.J.A.V.D.; Peters, O.C.J.J. Tensile and compressive properties of flax fibres for natural fibre reinforced composites. J. Mater. Sci. 2002, 37, 1683-1692. [CrossRef]

43. Madsen, B.; Aslan, M.; Lilholt, H. Fractographic observations of the microstructural characteristics of flax fibre composites. Compos. Sci. Technol. 2016, 123, 151-162. [CrossRef] 